\title{
ESCOLA TÉCNICA FEDERAL DE JANUÁRIA: PERCURSO HISTÓRICO, REGIONALIDADE, PRÁTICAS EDUCATIVAS
}

\author{
Bruno Vieira da Silva*; Helder de Moraes Pinto \\ *E-mail: bruno.silva@ifnmg.edu.br \\ Universidade Federal dos Vales do Jequitinhonha e Mucuri, Brasil \\ DOI: 10.15628/rbept.2020.5939 \\ Artigo submetido em abr/2019 e aceito em fev/2020
}

\begin{abstract}
RESUMO
O presente artigo utiliza-se da análise histórica para investigar um objeto no campo da educação profissional; trata-se da Escola Técnica Federal de Januária e sua busca de alternativa que propiciasse o progresso econômico regional, no final do século XX. Investigação de natureza qualitativa, esta pesquisa desenvolveu-se a partir dos métodos da pesquisa bibliográfica e documental, em arquivos da própria Escola e do Ministério da Educação. Os resultados da análise demonstram que a citada instituição, tomando como referência características e potencialidades duma região, dentro da grande bacia hidrográfica do Médio São Francisco, utilizou o curso Técnico em Agropecuária para assumir o papel de fomentadora da produção econômica, a partir da educação profissional, no âmbito da potencialidade da cultura ribeirinha.
\end{abstract}

Palavras-Chave: História da Educação Profissional. Práticas de ensino. Potencial da Cultura Local. Cultura Ribeirinha.

\section{FEDERAL TECHNICAL SCHOOL OF JANUARY: HISTORICAL TRACK, RELATIONSHIP WITH REGIONAL POTENTIAL, EDUCATIONAL PRACTICES}

\begin{abstract}
This article uses historical analysis to investigate an object in the field of professional education; it is the Federal Technical School of Januaria and its search of alternative that propitiated the regional economic progress, at the end of century XX. Research of a qualitative nature, this research was developed from the methods of bibliographical and documentary research, in archives of the School itself and the Ministry of Education. The results of the analysis show that the mentioned institution, taking as a reference characteristics and potentialities of a region, within the large hydrographic basin of the Middle São Francisco, used the Technical Course in Agropecuaria to assume the role of fomenter of the economic production, from the professional education, in the scope of the potential of the riverside culture.
\end{abstract}

Keywords: History of Professional Education. Teaching practices. Potential of Local Culture. Ribeirinha Culture. 


\section{INTRODUÇÃO}

A Educação Profissional de Nível Técnico no Brasil tem provocado, na atualidade, discussões sobre os rumos das dinâmicas impostas pelo desenvolvimento científico-tecnológico face ao eixo trabalho e educação. A história desta estratégica modalidade educacional vem sendo analisada a fim de colaborar no seu planejamento presente e futuro.

Sob o olhar do Ministério da Educação, esta modalidade educacional é datada desde 1909, tem o seu marco inicial a criação de 18 unidades de Escolas de Aprendizes e Artífices no governo do então presidente Nilo Peçanha. Embora repletas de intenções políticas, sobretudo relacionadas aos seus posicionamentos, e a penetração do ideário positivista em meio a um surto de industrialização na época. Tais entidades apresentavam-se como ferramenta estratégica estatal, atrelada a lógica dos interesses de cunho socioeconômico. Visava educar a população menos favorecida com o preparo técnico e intelectual. E tinha interesses também, em atender a uma demanda cada vez mais necessária na sociedade que se expandia com expectativas de modernização, leia-se, uma demanda por mão de obra qualificada, conforme Decreto Imperial ํo 7.566 de 1909.

O âmago da maior expressão desta história de 110 anos centra-se na grande relevância da inclusão social daqueles que estão fora do processo produtivo e do contexto social. Mas esta educação guarda, também, traços de uma dualidade enfatizada nas diversas evidências de contradições entre a formação geral propedêutica, para os filhos das elites, e a formação de ofícios tencionada pelo mundo do trabalho, para os filhos das classes populares. (Cf. KUENZER, 2007).

Diante das características originárias desta modalidade educacional, a presente pesquisa analisou a grade curricular do curso Técnico em Agropecuária ${ }^{1}$ em três configurações assumidas pela Escola Técnica Federal de Januária. Esta pesquisa adentra aos diálogos proferidos tanto por fontes bibliográficas quanto documentais, de forma a almejar uma aproximação com a identidade deste lócus de pesquisa.

Este artigo faz parte de uma pesquisa de mestrado a qual analisa os documentos regulatórios do curso Técnico em Agropecuária e seu contexto de produção no IFNMG campus Januária. Neste sentido, analisou-se a grade curricular do supracitado curso nos anos de 1993 a 2008, para identificar as prováveis estratégias de formação adotadas pela Escola Técnica Federal de Januária, na busca de uma alternativa que propiciasse, em alguma medida, desenvolvimento econômico dentro de sua abrangência regional, lembre-se

\footnotetext{
${ }^{1} \mathrm{O}$ curso Técnico em Agropecuária foi durante 42 anos a única formação ofertada pela Escola Técnica Federal de Januária, e atualmente constitui-se como o curso mais antigo desta.
} 
as "ribeiras" e as proximidades do Rio São Francisco ${ }^{2}$, no norte de Minas Gerais.

A metodologia utilizada na presente pesquisa caminha de encontro às documentações (primárias) produzidas interna e externamente ao IFNMG campus Januária, e serão analisadas à luz da metodologia e das ferramentas da pesquisa documental, bem como da análise bibliográfica, uma vez que confrontaremos o que está registrado nos documentos da instituição alvo com as legislações da época em questão, isso claro, orientados por noções oferecidas por bibliografia pertinente ao tema.

Como uma maneira de nortear as discussões sobre as intencionalidades presentes no "momento social" da confecção das grades curriculares do curso Técnico em Agropecuária, ao longo do recorte temporal escolhido para este artigo, elencar-se-á a matriz curricular do mencionado curso na década de 90 e nos anos 2000.

Por possibilitar realizar alguns tipos de reconstrução histórica de uma instituição educacional, o documento escrito constitui uma fonte extremamente relevante para todas as pesquisas na área das ciências sociais. Neste sentido, conforme Cellard (2008, p. 295) o documento é "insubstituível em qualquer reconstituição referente a um passado relativamente distante, pois não é raro que ele represente a quase totalidade dos vestígios da atividade humana em determinadas épocas.". E o documento, também, permanece como o único testemunho de atividades particulares ocorridas num passado recente segundo o mesmo autor ${ }^{3}$.

\section{HISTÓRICO CURRICULAR DO CURSO TÉCNICO EM AGROPECUÁRIA: ANÁLISES E DISCUSSÕES}

O curso técnico em Agropecuária possui uma relação de continuidade intrínseca à Escola Técnica Federal de Januária, a supracitada instituição antes de se tornar escola, apresentava-se, para a comunidade januarense, como um posto de fomento agrícola passando a ser escola em 1960. Com o passar dos anos juntamente ao "amadurecimento" das práticas de ensino agropecuário, surge na iniciante instituição, um construto inclinado para as áreas agrárias, pois segundo Magalhães

\footnotetext{
2 Para maiores informação recomenda-se a leitura do Decreto mineiro no 45.285, de 11/01/2010 que Institui o Comitê da Bacia Hidrográfica dos Afluentes Mineiros do Médio São Francisco

${ }^{3}$ Faz-se necessário enfatizar que o acolhimento deste entendimento não se faz de forma integral para esta pesquisa. Concorda-se que a fonte documental é extremamente importante para as pesquisas sócio-históricas. Entretanto, não é a única, a história oral tem um papel relevante nessa missão de investigar aspectos sócio-históricos no passado recente.
} 
a institucionalização da educação escolar como processo histórico desenvolve-se no momento em que [...] a estrutura escolar apresenta uma internalidade complexa e identitária, associada a uma influência determinante na realidade. (MAGALHÃES, 2004, p. 39).

As transformações identitárias no contexto escolar em tela ocorreram paralelamente aos movimentos políticos que muitas vezes culminaram na mudança de nomenclatura ${ }^{4}$ da instituição, pois, considera-se que

\begin{abstract}
as legislações, mais do que documentos jurídicos são expressão da luta política em torno da função da educação, percebemos que as instituições promovem uma recontextualização das normas em suas realidades específicas e, assim, as reconstroem no âmbito de outras disputas travadas em seu próprio interior. (FRIGOTTO E CIAVATTA, 2006, p. 283).
\end{abstract}

Desta forma, constata-se que as mudanças de nomenclatura "impostas" à mencionada instituição, veio a dar face aos movimentos políticos e sociais que ocorriam na época em questão. "Afinal, a educação escolar é uma dimensão estratégica para políticas que visam a inserção de todos nos espaços da cidadania social e política e mesmo para reinserção no mercado profissional.". (CURY, 2006, p. 07).

De acordo com as discussões proferidas por Kuenzer (2007), Ghiraldelli (2003), a educação profissional no Brasil sempre foi encarada como uma ferramenta governamental em que se empreendiam esforços com intuito de elevar a produtividade, bem como, o enquadramento de uma parcela da população ao mercado de trabalho, porém, obtiveram-se resultados concretos mais afinados aos setores da economia do que para equalização social.

Neste sentido, muitas foram às discussões que impactaram as filosofias educacionais, estas por sua vez, influenciaram no curso Técnico em Agropecuária durante os processos de transformações que refletiram na reestruturação administrativa e educacional (nomenclaturas ou movimentos político-pedagógicos), bem como, mudanças de filosofias vivenciadas no cerne da instituição pesquisada.

Na década de 1990, o Ensino Médio na instituição, nomeada, na época, como Escola Agroténica Federal de Januária - EAFJ, era concomitante com o Curso Técnico em Agropecuária, conforme evidenciado no principal objetivo do Plano de Curso do Ensino Médio (1994, p. 03),

\footnotetext{
${ }^{4}$ As mudanças de nomenclaturas referenciadas neste trabalho vão de encontro a uma perspectiva que as enxergam como sendo o resultado de um processo macro ocorrido a partir das políticas socioeducativas voltadas para a educação profissional no Brasil.
} 
"Desenvolver educação de nível básico, oferecendo o Ensino Médio concomitante ao Ensino Profissionalizante do Curso Técnico em Agropecuária.". E, mais tarde, veio a encontrar respaldo legal no Art. 40 da Lei 9.394 /96 (Diretrizes e Bases da Educação), "A educação profissional será desenvolvida em articulação com ensino regular ou por diferentes estratégias de educação continuada, em instituições especializadas ou no ambiente de trabalho". Neste sentido, a grade curricular do Curso Técnico em Agropecuária era organizado da seguinte forma:

Figura 10: Quadro - Grade Curricular do Curso Técnico em Agropecuária nos Anos de 1990

\begin{tabular}{|c|c|c|c|}
\hline Ano & $\begin{array}{c}\text { Quantidade de } \\
\text { alunos }\end{array}$ & Série & Disciplinas \\
\hline 1991 & 317 & $1^{a}$ Ano & $\begin{array}{c}\text { Língua Portuguesa, Literatura Brasileira, } \\
\text { Matemática, Biologia, Química, Programa da } \\
\text { Saúde, Geografia, História, Educação Moral e } \\
\text { Cívica. Educação Artística, Cooperativismo, } \\
\text { Agricultura I, Zootecnia I, Educação Física, } \\
\text { Ensino Religioso. }\end{array}$ \\
\hline 1992 & 366 & $2^{a}$ Ano & $\begin{array}{c}\text { Língua Portuguesa, Literatura Brasileira, } \\
\text { Matemática, Biologia, Química, Organização } \\
\text { Social e Política do Brasil, Desenho e } \\
\text { Topografia, Agricultura II, Zootecnia II, } \\
\text { Mecanização Agrícola, Indústrias Rurais, } \\
\text { Educação Física. }\end{array}$ \\
\hline 1993 & 352 & $3^{\underline{a}}$ Ano & $\begin{array}{c}\text { Língua portuguesa, Literatura Brasileira, } \\
\text { Redação e Expressão, Matemática, Física, } \\
\text { Estudos Regionais - Sociologia e Extensão } \\
\text { Rural, Irrigação e Drenagem, Administração e } \\
\text { Ecologia Rural, Construções e Instalações } \\
\text { Rurais, Agricologia III, Zootecnia III, Educação }\end{array}$ \\
\hline
\end{tabular}

Física.

Fonte: Secretaria do Ensino Médio IFNMG campus Januária.

Elaborado pelo autor.

O curso Técnico em Agropecuária, desde a sua oficialização em 1964, Curso Ginasial Agrícola, até o ano de 2001 foi o único curso ofertado pela Escola Técnica Federal de Januária. Este aspecto justifica o alto número de alunos matriculados neste período. Ademais, era um curso concomitante com o ensino médio, o aluno que ingressava nesta instituição tinha ciência que 
para conseguir se formar, necessariamente, teria que completar as etapas inerentes à profissionalização do curso Técnico em Agropecuária.

Um fato intrigante do ponto de vista identitário recai sobre algumas disciplinas ministradas a época, como: Educação Moral e Cívica, Organização Social e Política do Brasil, Estudos Regionais - Sociologia e Extensão Rural e Educação Física. Percebe-se com as três primeiras disciplinas, uma formação correlacionada à práxis educativa, a qual valoriza o conhecimento voltado para as relações sociais e as reflexões políticas, econômicas e morais. Encontram-se, também, embasamentos para tais disciplinas na ideia de uma sociedade, ainda, influenciada pelos traços do Regime Civil Militar cujo os princípios baseavam-se na ordem, ética, estética e o patriotismo, (GHIRALDELLI, 2003). Bem como numa visão produtivista, segundo (SAVIANI, 2008, p. 298). Isto por que na visão destes autores, ao subsidiar os alunos de aportes sociais que condicionam comportamentos "dóceis", justificando, assim, sua inércia diante do cenário social posto; favorece a aceitação destes; de outro lado, cria-se "terreno fértil" a incorporação de aspectos prestigiados pelas instituições econômicas obstinadas ao lucro.

Ao exibir tal característica curricular educacional em uma determinada instituição escolar, compete-nos ponderar sobre o marco legal que engendra as mencionadas características pedagógicas, para tanto, 0 Decreto-Lei $n^{\circ}$ 869 de 1969 institui em caráter obrigatório, como disciplina, e também, como prática educativa, a Educação Moral Cívica, nas escolas de todos os graus e modalidades dos sistemas de ensino no país. Ainda neste decreto no artigo 3o é previsto a oferta, obrigatória, da disciplina Organização Social e Política do Brasil. Ambas foram adotadas em substituição às matérias de Filosofia e Sociologia e ficaram caracterizadas pela transmissão da ideologia do regime autoritário ao exaltar o nacionalismo e o civismo dos alunos e privilegiar o ensino de informações factuais em detrimento da reflexão e da análise. (MENEZES, 2001, et $\mathrm{al}^{5}$ ).

Mais tarde, a Lei n․ 5.692 de 1971 fixa diretrizes e bases para o ensino de $1^{\circ}$ e $2^{\circ}$ grau, em seu artigo $7^{\circ}$ diz que "será obrigatória a inclusão de Educação Moral e Cívica, Educação Física, Educação Artística e Programas da Saúde nos Currículos plenos dos estabelecimentos de $1^{\circ}$ e $2^{\circ}$ graus.".

A disciplina Educação Física entra neste contexto, como um instrumento capaz de levantar a bandeira da capacidade física para desempenhar serviços pertinentes às áreas do curso Técnico em

5 MENEZES, Ebenezer Takuno de; SANTOS, Thais Helena dos. Verbete OSPB (Organização Social e Política Brasileira). Dicionário Interativo da Educação Brasileira Educabrasil. São Paulo: Midiamix, 2001.2 Disponível em: $<$ http://www.educabrasil.com.br/ospb-organizacao-social-e-politica-brasileiral>. Acesso em: 29 de ago. 2018. 
Agropecuária, bem como aulas práticas. Observando-se assim, o prontuário médico dos alunos, corrobora claramente para a preocupação com a saúde do indivíduo, isso, pensando na disponibilidade do aluno para o trabalho. Observou-se também, nos históricos dos ex-alunos do supracitado curso, que a grande maioria solicitou a Certidão de tempo de Aluno Aprendiz como requisito para a averbação de tempo de serviços junto ao INSS - Para efeito de aposentadoria. Conforme texto a seguir:

\begin{abstract}
O interessado foi aluno aprendiz deste Instituto Federal do Norte de Minas Gerais - Campus Januária, tendo sido remunerado, indiretamente, pelo Orçamento da União na forma de parcela de renda auferida com a execução de projetos produtivos agrícolas, comercializados para terceiros através da Cooperativa-Escola dos alunos, como compensação das atividades pedagógicas práticas exercidas nos campos de culturas e criações. Certidão conforme Súmula 96 do TCU e Parecer 07/96, de 07/03/96, da Procuradoria Jurídica deste Instituto. (HISTÓRICO ESCOLAR CURSO TÉCNICO EM AGROPECUÁRIA - IFNMG CAMPUS JANUÁRIA).
\end{abstract}

A Instrução Normativa ํo. 27 de 30 de abril de 2008 é o mais recente documento expedido pelo INSS que trata da concessão de contagem de tempo de Aluno Aprendiz. De acordo com a mencionada Instrução Normativa, apoiada também, no Decreto-Lei ํo. 4.073, de 30 de janeiro de 1942, Decreto-Lei 8.590 de 8 de janeiro de 1946 e Decreto №. 3.048 de 6 de maio de 1999 o fato jurídico relacionado ao segurado egresso de escola Agrícola ou Agrotécnica Federal, que com seus serviços escolares geraram bens que foram comercializados pelas unidades escolares, usando para tal 0 instrumento "cooperativa" que se apropriava dos resultados financeiros, e em contrapartida forneceram gratuitamente ensino, alojamento, alimentação, dentre outros benefícios, caracteriza, portanto, vínculo empregatício, e o exaluno, assegurado pela legislação em vigor passa a contar com o direito a contagem do tempo de serviço prestado na condição de aluno aprendiz, para fins previdenciários.

No ano de 2.000 a grade curricular do curso Técnico em Agropecuária sofre alteração, influenciada, em parte, pelas mudanças relativas à nova função institucional e social sugerida pela Lei 9.394/96 e suas

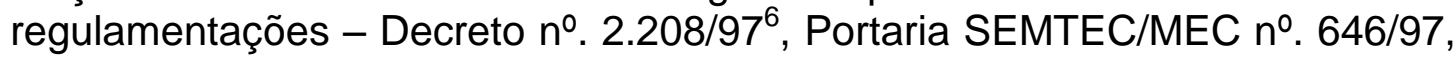
Parecer CEB/CNE ํo. 15/98 e ํo. 16/99, Resoluções CEB/CNE no․ 03/98 e ํo. 04/99.

\footnotetext{
6 "Além de determinar a separação do Ensino Médio do Ensino Técnico, por meio de duas matrículas, instituindo o ensino concomitante interno ou externo e o incentivo ao Ensino Técnico Pós-médio, o Decreto n. 2.208/97 estabelece três níveis de educação profissional: o nível Básico, o Técnico e o Tecnológico". (FRIGOTTO e CIAVATTA, 2006, p. 313).
} 
Neste momento, os movimentos sociais, políticos e econômicos no cenário brasileiro exigiam do governo federal uma atitude sobre a educação profissional. Segundo Frigotto e Ciavatta (2006) desde o início da redemocratização brasileira, que o tema da finalidade das Escolas Técnicas Federais é arduamente debatido por segmentos conservadores e progressistas da sociedade.

\begin{abstract}
Quanto aos primeiros, a crítica centrava-se em seu alto custo e no distanciamento do mercado de trabalho, demonstrado pelo elevado número de alunos que se dirigiam ao Ensino Superior. Com relação aos progressistas, questionava-se a concentração de recursos públicos em instituições que serviam predominantemente ao capital, com atendimento seletivo e restrito à população. (FRIGOTTO $E$ CIAVATTA, 2006, p. 287).
\end{abstract}

O Curso Técnico em Agropecuária na Escola Técnica Federal de Januária passa a ser distribuído em módulo, dois módulos por ano, ou seja, a cada seis meses um módulo era cursado. Esta nova forma de organização da matriz curricular do curso passou a valorizar não mais exclusivamente às disciplinas desassociadas de uma intencionalidade profissional, mas sim o Módulo, entendido como um conjunto de competências e habilidades necessárias ao pleno desempenho profissional.

\title{
Figura 11: Quadro - Matriz Modular do Curso Técnico em Agropecuária
}

\section{MÓDULO DE QUALIFICAÇÃO TÉCNICA}

\begin{tabular}{|c|c|}
\hline Período & Módulo \\
\hline $1^{\circ}$ semestre & Gestão e Empreendimentos com Olericultura \\
\hline $2^{\circ}$ semestre & Gestão e Empreendimentos com Culturas Anuais \\
\hline $3^{\circ}$ semestre & Gestão e Empreendimentos com Fruticultura \\
\hline $4^{\circ}$ semestre & Gestão e Empreendimentos com Animais de Pequeno Porte \\
\hline $5^{\circ}$ semestre & Gestão e Empreendimentos com Animais de Médio Porte \\
\hline $6^{\circ}$ semestre & Gestão e Empreendimentos com Animais de Grande Porte \\
\hline
\end{tabular}

Fonte: Plano de curso - Técnico em Agropecuária - 2001/ Secretaria do Ensino Médio IFNMG campus Januária. Elaborado pelo Autor.

Percebe-se no quadro que ilustra a matriz modular do supracitado curso a ênfase dada às palavras Gestão e Empreendimentos, quais faz relação ao novo conceito neotecnicista da nova organização laboral, reflexo 
decorrente das mudanças ocorridas no mundo do trabalho pela globalização econômica e pela reestruturação produtiva.

Os princípios neotecnicistas ${ }^{7}$ influenciaram os projetos pedagógicos na Escola Técnica Federal de Januária no início dos anos 2.000, na visão de Kuenzer (2007), tais princípios insuflaram procedimentos de gerenciamento, qualidade e competitividade no universo escolar. Desta forma a ocorrência das elencadas palavras demonstra a flexibilidade assumida pela pedagogia da educação em contexto de instituições educativas técnico-profissionais, o que corrobora também, para o entendimento que enxerga estas mudanças como passivas de impactarem o percurso identitários destas instituições educacionais.

Outro ponto pôde ser observado na matriz curricular do curso, houve a separação do Ensino Médio do ensino profissionalizante, o aluno ao ingressar na Escola Técnica Federal de Januária não tinha mais a obrigatoriedade de cursar necessariamente o curso de Técnico em Agropecuária. Portanto a partir do ano 2.000 a grade curricular do ensino básico nível médio passa a ser distribuído em ciclos de três anos da seguinte forma:

\section{Figura 12: Quadro - Matriz Curricular do Curso Técnico em Agropecuária - Formação Geral}

\section{EDUCAÇÃO GERAL}

Ano Disciplinas

2001/2002/2003 Língua portuguesa, Língua Estrangeira Inglês, Matemática, História, Geografia, Programa da Saúde, Química, Biologia, Educação Física,

Física, Educação Artística, Ensino Religioso, Literatura Brasileira, Educação Moral e Cívica, Redação e Expressão.

Fonte: Plano de Curso - Técnico em Agropecuária - 2001/ Secretaria do Ensino Médio IFNMG campus Januária. Elaborado pelo Autor.

A organização disciplinar do ensino regular médio passa a valorizar a formação propedêutica desassociada da preparação para o trabalho. Segundo Frigotto, Ciavatta e Ramos (2010, p. 43) "o Decreto n. 2.208/97

${ }^{7}$ As mudanças no mundo do trabalho ocorridas nas últimas décadas, em função da reestruturação do sistema capitalista (e a conseqüente alteração do sistema de produção taylorista/fordista pelo toyotismo), trouxeram no seu bojo novas determinações para a escola e para a organização do trabalho pedagógico no seu interior. (MIRA; ROMANOWSKI, 2009, p. 10.212). 
interrompeu, ao forçar a adequação da realidade à lei, proibindo que o ensino médio propiciasse também a formação técnica".

A partir de então, o novo discurso empregado na formação Técnica no presente locus de pesquisa refere-se a um trabalhador versátil, apresentando, portanto, capacidade intelectual que the permita adaptar-se à produção flexível. Bem como, capacidades de comunicar-se adequadamente com códigos e sinais de língua nacional e estrangeira, autonomia moral, através da capacidade de enfrentar as novas situações que exigem posicionamentos éticos; comprometer-se com o trabalho, entendido em sua forma mais ampla de construção do homem e da sociedade, através da responsabilidade, da criticidade, da criatividade. (KUENZER, 2007). Esta característica curricular faz jus a ideia contida na educação libertária e suas influências trazidas na virada do século XXI.

Os alunos que optavam em cursar tanto o curso regular de nível médio concomitante com o curso profissional de Técnico em Agropecuária ou apenas este último cursavam as disciplinas abaixo distribuídas em ciclos de três anos: Figura 13: Quadro - Matriz Curricular do Curso Técnico em
Agropecuária - Formação Técnica

FORMAÇÃO ESPECIAL/ AULA INSTRUMENTAL

Ano

$2001 / 2002 / 2003$

Agricultura Geral, Zootecnia Geral, Culturas Temporárias, Culturas Anuais

I, Culturas Anuais II, Culturas permanentes I, Animais de Pequeno Porte,

Culturas Permanentes II, Animais de Médio Porte I, Animais de Médio

Porte II, Introdução a Agroindústria, Animais de Grande Porte I,

Mecanização Agrícola I, Mecanização Agrícola II, Animais de Grande

Porte II, Desenho Técnico, Irrigação e Drenagem I, Irrigação e Drenagem

II, Topografia Geral, Indústrias Rurais, Construções Rurais Administração e Economia I, Administração e Economia Rural II, ESTÁGIO SUPERVISIONADO.

Fonte: Plano de Curso - Técnico em Agropecuária - 2001/Secretaria do Ensino Médio IFNMG campus Januária. Elaborado pelo Autor.

Com as mudanças advindas na virada para o século XXI na supracitada instituição impactaram não somente a grade curricular dos cursos, mas também o sistema de avaliação utilizado nesta escola. Neste momento a avaliação por conceito ganha destaque, e é fortemente influenciada pela Pedagogia das Competências. Neste sentido o sistema de avaliação apresentou-se da seguinte forma: 
Figura 14: Quadro - Matriz Curricular do Curso Técnico em Agropecuária - Sistema de Avaliação

\section{SISTEMA DE AVALIAÇÃO A PARTIR DO ANO 2000}

Legenda para Aspectos Atitudinais

(Sim) (Não) (AV - às vezes)

Conceito
A. Participativo

\section{Características}

- Interessado, Questionador, observador, desenvolve trabalhos propostos; Acompanha a explicação e participa das aulas expositivas.

\section{B. Comprometido}

\section{- Pontual; Respeito às normas disciplinares e de convivência; Freqüente/ Justificativa de Faltas; Organizado; Responsável; Realiza} as atividades propostas.

\section{ITENS AVALIADOS DE ACORDO AS COMPETÊNCIAS ATINGIDAS PELOS ALUNOS}

(AC)

$(A P)$

(NA)

\section{Adquiriu a Competência}

Adquiriu Parcialmente

Não Adquiriu a Competência

Sem condições de Avaliação

Fonte: Plano de Curso - Técnico em Agropecuária - 2001/Secretaria do Ensino Médio IFNMG campus Januária. Elaborado pelo Autor.

Os princípios neotecnicistas laçaram componentes de competitividade no sistema de avaliação do Curso Técnico em Agropecuária ao instituir o conceito como critério avaliativo, o termo Participativo e Comprometido valoriza características típicas exaltadas pela nova organização do mercado de trabalho. Os critérios $(A C),(A P),(N A)$ e $(S C)$ institui, desde a escola, a noção de competitividade no educando; assim, "a educação deve dar conta da formação de um trabalhador com certos tipos de competências, habilidades e virtudes, cujo aprendizado deve ocorrer antes de sua inserção no mercado de trabalho.". (MIRA; ROMANOWSKI, 2009, p. 10.214).

No ano de 2008 já na configuração Instituto Federal de Educação, Ciência e Tecnologia do Norte de Minas Gerais - IFNMG Campus Januária, o Curso Técnico em Agropecuária passa a ser nomeado de Curso de Educação Profissional Técnica de Nível Médio em Meio Agropecuária Integrado ao Ensino Médio. Autorizado pela resolução CD no 03/2007, de 11 de outubro de 2007.

A justificativa para desenvolver um curso técnico integrado, num momento fortemente guiado por uma interdisciplinaridade educacional nos 
dias atuais, se baseia no seguinte trecho do Plano de Curso - Técnico em Agropecuária/2008:

O Curso Técnico em Agropecuária integrado ao Ensino Médio propõe trabalhar com a concepção mais ampla de educação, de modo a incorporar todas as dimensões educativas que ocorrem no âmbito das relações sociais que objetivam a formação humana nas dimensões social, política e produtiva. Tal perspectiva implica em reconhecer e considerar a configuração da sociedade local e regional, sua inserção em planos mais amplos e suas possibilidades nas dinâmicas internas. Essa nova forma de organização deve contemplar conhecimentos, capacidades e atitudes específicas não só de uma ocupação, mas, também, da área profissional da qual deriva. (PLANO DE CURSO - TÉCNICO EM AGROPECUÁRIA, 2008, p. 09).

Percebe-se que os aspectos provenientes do movimento neotecnicista perpetuam-se nessa nova organização curricular ao valorizar a flexibilidade das competências adquiridas pelo educando. Salienta-se também, as características da educação libertadora nesse processo de contexto educacional da Escola Técnica Federal de Januária.

Neste sentido a grade curricular do curso integrado de Técnico Agropecuária no ano de 2008 passa a se organizar da seguinte forma:

\section{Figura 15: Quadro - Matriz Curricular do Curso Técnico em Agropecuária Integrado}

\begin{tabular}{|c|c|c|c|}
\hline \multirow{5}{*}{ 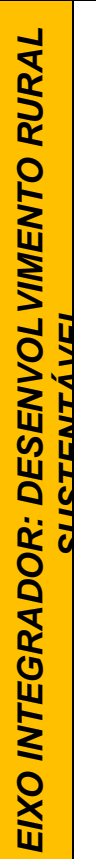 } & \multicolumn{3}{|c|}{ MATRIZ CURRICULAR DO CURSO } \\
\hline & O & Linguagens & $\begin{array}{c}\text { Disciplinas } \\
\text { Português } \\
\text { Artes } \\
\text { Educação Física }\end{array}$ \\
\hline & $\frac{1}{I}$ & Matemática & Matemática \\
\hline & U & Ciências da Natureza & $\begin{array}{c}\text { Biologia } \\
\text { Física } \\
\text { Química }\end{array}$ \\
\hline & & Ciências Humanas & $\begin{array}{c}\text { História } \\
\text { Geografia } \\
\text { Filosofia } \\
\text { Sociologia }\end{array}$ \\
\hline
\end{tabular}




\begin{tabular}{|c|c|c|}
\hline \multirow{14}{*}{ 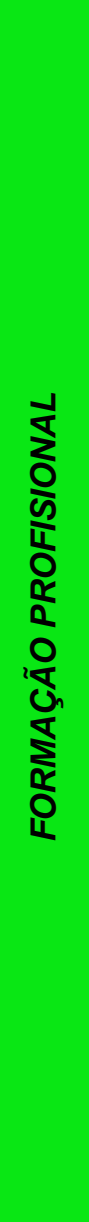 } & Parte Diversificada & $\begin{array}{c}\text { Inglês } \\
\text { Espanhol } \\
\text { Língua Estrangeira } \\
\text { Seminários Temáticos } \\
\text { Integradores }\end{array}$ \\
\hline & \multicolumn{2}{|l|}{ Agricultura Geral e Olericultura } \\
\hline & \multicolumn{2}{|l|}{ Desenvolvimento e Extensão Rural } \\
\hline & \multicolumn{2}{|l|}{ Zootecnia Geral e Pequenas Criações } \\
\hline & \multicolumn{2}{|l|}{ Culturas Anuais e Forragicultura } \\
\hline & \multicolumn{2}{|l|}{ Desenho Técnico e Topografia } \\
\hline & \multicolumn{2}{|l|}{ Mecanização Agrícola } \\
\hline & \multicolumn{2}{|l|}{ Processamento Agroindustrial } \\
\hline & \multicolumn{2}{|l|}{ Produção de Monogástricos } \\
\hline & \multicolumn{2}{|l|}{ Construções Rurais e Ambiência } \\
\hline & \multicolumn{2}{|l|}{ Culturas Perenes e Fruticultura } \\
\hline & \multicolumn{2}{|l|}{ Gestão Agropecuária } \\
\hline & \multicolumn{2}{|l|}{ Irrigação e Drenagem } \\
\hline & \multicolumn{2}{|l|}{ Produção de Ruminantes } \\
\hline
\end{tabular}

Fonte: Secretaria do Ensino Médio IFNMG campus Januária.

Elaborado pelo Autor.

Segundo o Plano de Curso - Técnico Agropecuário Integrado ao Ensino Médio 2008, o processo de avaliação consiste em um trabalho contínuo de regulação da ação pedagógica, realizada de forma processual, com caráter diagnóstico e formativo voltada para o pleno desenvolvimento do indivíduo e da aprendizagem, o preparo para o exercício da cidadania e a qualificação para o trabalho.

No Campus Januária a avaliação do processo de ensinoaprendizagem é contínua e cumulativa e tem por fundamento uma visão crítica sobre o ser humano, a sociedade, a natureza, a educação, a ciência, a cultura, a tecnologia e a arte. Deve criar condições para a participação e desenvolvimento dos alunos, considerando-os como sujeitos da ação educativa e deve considerar as competências constantes no perfil profissional previsto no projeto formativo do curso. (PLANO DE CURSO - 
TÉCNICO AGROPECUÁRIO INTEGRADO AO ENSINO MÉDIO, 2008, p. 62).

Ao analisar a grande curricular do supramencionado curso em três diferentes configurações políticas é preciso ter clareza para percebe que projeto educacional estamos ajudando a construir e quais são suas bases teóricas. "Porque a hegemonia das idéias neoliberais, que procura se confundir com os discursos mais progressistas, tem levado a uma série de confusões conceituais, que influenciam sobremaneira em nossas práticas escolares.". (MIRA; ROMANOWSKI, 2009, p. 10.217).

\section{CONSIDERAÇÕES FINAIS}

A partir da revisão de literatura proposta e da análise às grades curriculares do curso Técnico em Agropecuária, é possível concluir que o histórico curricular do referido curso evidencia, em sua essência, interpretações que convergem para um ensino multifuncional, no qual a educação tecnológica se apresenta no campo educacional do locus de pesquisa sob duas perspectivas. Uma que aborda conhecimentos associados às tecnologias utilizadas nos processos de produção e, assim, pode formar pessoas para o manejo social e profissional dessas tecnologias para ocuparem um espaço específico na divisão social e técnica do trabalho. E a outra perspectiva defende um ideário, em termos teóricos e práticos, que propiciasse a superação da concepção educacional burguesa que se pauta pela dicotomia entre trabalho manual e trabalho intelectual, e entre instrução profissional e instrução geral. (FRIGOTTO; CIAVATTA; RAMOS, 2010).

Desta forma, o conceito de educação tecnológica, neste âmbito institucional, ganha o mesmo significado de educação politécnica. Pois

a educação politécnica não é aquela que só é possível em outra realidade, mas uma concepção de educação que busca, a partir do desenvolvimento do capitalismo e de sua crítica, superar a proposta burguesa de educação que potencialize a transformação estrutural da realidade. (FRIGOTTO; CIAVATTA; RAMOS, 2010, p. 44).

Tal constatação ganha força, pois é reforçado pelo projeto - Plano de Curso Técnico em Agropecuária do ano de 1998, onde diz que

Considerando a oferta de educação para a população rural essencialmente o público alvo de uma Instituição Federal de Educação Tecnológica na área de agropecuária, ou sua clientela potencial, entendemos que as adaptações necessárias à adequação das peculiaridades do setor agropecuário de que trata 0 art. 6ำ da Portaria 646/97, passa pela defesa da manutenção do 
sistema escola-fazenda (com as devidas e necessárias mudanças) e pelo oferecimento do Ensino médio, alvo da presente proposta pedagógica, com concomitância interna com o Curso Profissionalizante. (PLANO DE CURSO TÉCNICO EM AGROPECUÁRIA, 1998).

Entende-se a partir desta citação, e todo o conjunto de ideias implícitas no documento de que se trata, que houve a preocupação ao atendimento de uma proposta educacional para com a educação profissional ofertadas pelas instituições educacionais integrantes da Rede Federal de Educação Tecnológica.

A referenciada portaria em seu Artigo $6^{\circ}$ defende que "as instituições federais de educação tecnológica que ministram cursos do setor agropecuário poderão organizá-los de forma a atender as peculiaridades de sua localização e metodologias aplicadas a esse ensino.". (PORTARIA MEC 646/97). Com base nesta deliberação, percebe-se a congruência do que foi inferido acima, à ideia de movimentos sociais que viram nas instituições federais de ensino tecnológico um potencial instrumento, capaz de fomentar o progresso econômico com base nas características da cultura regional da instituição.

Imbuído no anseio de identificar as prováveis estratégias de formação adotadas pela Escola Técnica Federal de Januária, na busca de uma alternativa que propiciasse, em alguma medida, desenvolvimento econômico dentro de sua abrangência regional. Chega-se aos resultados que a partir da sua estrutura curricular o enfoque dados às demandas da cultura econômica regional é potencializado na instituição. Para tanto, entende-se que a nova configuração social assumida na contemporaneidade, força as pedagogias escolares atuais a se comprometerem com o estabelecimento de uma relação entre o aluno e o conhecimento que verdadeiramente integrasse conteúdo e método, de modo a propiciar o domínio intelectual das práticas sociais e produtivas. (FERREIRA; et al, 2008).

Apoiando nesta forma de raciocínio, acredita-se que o curso Técnico em Agropecuária, curso fortemente enraizado na identidade institucional da Escola Técnica Federal de Januária, corroborou por representar uma materialidade simbólica perante a comunidade escolar e microrregional. Neste sentido, conclui-se na presente pesquisa que o curso Técnico em Agropecuária, diante de sua relevância institucional e microrregional, desempenhou não só as funções que vos é de obrigação. Mas, também assumiu o papel de promovedor do fomento da produção econômica, no âmbito da potencialidade da cultura ribeirinha. 


\section{REFERÊNCIAS}

BRASIL. CNE/CEB. Resolução 04 de 26/11/1999. Institui as Diretrizes Curriculares Nacionais para a Educação Profissional de Nível Técnico [http://portal.mec.gov.br/setec/arquivos/pdf/legisla06.pdf. Acessado em 29/06/2018 às 20 horas].

CNE/CP. Parecer 29, de 03/12/2002. estabelece as Diretrizes Curriculares Nacionais Gerais para a Educação Profissional de Nível Tecnológico. Diário Oficial da União. 13/12/2002.

. Conselho Nacional de Educação. Parecer CNE/CEB no 15, de $1^{\circ}$ de junho de 1998. Trata das Diretrizes Curriculares Nacionais para o Ensino Médio. Brasília: 1998.

Conselho Nacional de Educação. Parecer CNE/CEB no 16, de 5 de outubro de 1999. Trata das Diretrizes Curriculares Nacionais para a Educação Profissional Técnica de Nível Médio. Brasília: 1999.

. Conselho Nacional de Educação. Parecer CNE/CEB no 5, de 4 de maio de 2011. Trata das Diretrizes Curriculares Nacionais para o Ensino Médio. Brasília: 2011.

. Conselho Nacional de Educação. Resolução CNE/CEB no 3, de 26 de junho de 1998. Institui as Diretrizes Curriculares Nacionais para o Ensino Médio. Brasília: 1998. Disponível em: http://portal.mec.gov.br/ cne/arquivos/pdf/rceb03_98.pdf. Acesso em: 25 out. 2012.

. Conselho Nacional de Educação. Resolução CNE/CEB no 4, de 8 de dezembro de 1999. Institui as Diretrizes Curriculares Nacionais para a Educação Profissional. Brasília, 1999. Disponível em: http://portal.mec. gov.br/dmdocuments/rceb004_99.pdf. Acesso em: 29 set. 2013.

Constituição da República Federativa do Brasil. -- Brasília : Supremo Tribunal Federal, Secretaria de Documentação, 2017.

Decreto no. 7.566 de 23 de setembro de 1909. Cria nas Capitais dos Estados da República Escolas de Aprendizes Artífices para o ensino profissional primário e gratuito. Coleções de Leis do Brasil. Imprensa Nacional: Rio de Janeiro, 31 dez. 1909. Disponível em: http://portal.mec.gov.br/setec/arquivos/pdf3/decreto_7566_1909.pdf:

Acessado em 04 de jul. 2017.

. Lei no 5.571, de 28 de novembro de 1969. Denomina "Dia da Independência" a data de sete de setembro e traça normas para a sua comemoração. Brasília, DF. 1969.

. Lei no 13.005, de 25 de junho de 2014. Aprova o Plano Nacional de Educação (PNE) 2014-2024. Brasília: Câmara dos Deputados, Edições Câmara, 2014. 86 p. - (Série legislação; n. 125).

Lei no 10.172, de 09 de janeiro de 2001. Aprova o Plano Nacional de Educação (PNE). Diário Oficial da União, Brasília, DF, 10 jan. 2001. 
Lei no 9.394, de 20/12/1996. Estabelece as Diretrizes e Bases da Educação Nacional. Diário Oficial da República Federativa do Brasil, 23/12/1996.

Portaria no 646/97, de 14 de maio de 1997. Regulamenta a implantação do disposto nos artigos 39 a 42 da Lei no 9.394/96 e no Decreto n. 2.208/97 e dá outras providências, 1997.

CIAVATTA, M.; RAMOS, M. Ensino Médio e Educação Profissional no Brasil: dualidade e fragmentação. Retratos da Escola, v. 5, n. 8, p. 27-41, 2012.

CURY, Carlos Roberto Jamil. Legislação educacional brasileira. Rio de Janeiro: DP\&A, 2002.

FERREIRA, Naura Syria Carapeto; (org.); Et al. Gestão Democrática da Educação: atuais tendências, novos desafios. São Paulo: Cortez, 2008, 6 ed., p. 119.

FREIRE, Paulo. Educação Como Prática da Liberdade. Editora Paz e Terra LTDA. Rio de Janeiro. 1967.

FREITAS, Luiz Carlos. Crítica da Organização do Trabalho Pedagógico e da Didática. Tese de Livre Docência apresentada à Faculdade de Educação da UNICAMP. 1994.

Tecnicismo: ele está de volta. Blog do Freitas, 2016. Disponível em: https://avaliacaoeducacional.com/2016/08/26/tecnicismo-ele-esta-de-volta/.

Acessado em: 01 de abril de 2018.

FRIGOTTO, Gaudêncio. A produtividade da escola improdutiva: um (re)exame das relações entre educação e estrutura econômico-social capitalista. São Paulo: Editora Cortez, 1984-2010.

FRIGOTTO; CIAVATTA, Gaudêncio; Maria. A Formação do Cidadão Produtivo: a cultura de mercado no médio técnico. Brasília: Instituto Nacional de Estudos e Pesquisas Educacionais Anísio Teixeira. 2006.

FRIGOTTO; CIAVATTA; RAMOS, Gaudêncio; Maria; Marise. Ensino Médio Integrado: concepção e contradições. 2. ed. São Paulo. 2010

GHIRALDELLI, Paulo Júnior. Filosofia e História da Educação Brasileira. Editora Manole. Barueri, São Paulo. 2003.

Filosofia e história da educação brasileira: da colônia ao governo Lula / Paulo Ghiraldelli Jr. -2. Ed. - Barueri, SP: Manole, 2009.

INSTITUTO FEDERAL DO NORTE DE MINAS GERIAS. Disponível em: http://www.ifnmg.edu.br/menu-januaria/historico/55-portal/januaria/januariainstitucional/499-historico-completo-campus-januaria: Acessado em 04 de jan. 2018.

KUENZER, Acácia Zeneida. Ensino Médio: construindo uma proposta para os que vivem do trabalho. $5^{\mathrm{a}}$ ed. São Paulo: Cortez. 2007. 
MAGALHÃES, Justino Pereira de. Tecendo Nexos: história das instituições educativas/ Justino Pereira de Magalhães.-Bragança Pauliste: Editora Universitária São Francisco, 2004. 178p.

MENEZES, Ebenezer Takuno de; SANTOS, Thais Helena dos. Verbete OSPB (Organização Social e Política Brasileira). Dicionário Interativo da Educação Brasileira - Educabrasil. São Paulo: Midiamix, 2001. Disponível em: $<$ http://www.educabrasil.com.br/ospb-organizacao-social-e-politicabrasileira/>. Acesso em: 29 de ago. 2018.

PERRENOUD, Phillippe. Construir as Competências desde a Escola. Porto Alegre: Artes Médicas. 1999. Disponível em: http://abenfisio.com.br/wpcontent/uploads/2016/06/Construir-as-competec\%C3\%AAncias-desde-aescola.pdf. Acessado em: 21/07/2018 às 09:36.

SAVIANI, Dermeval. Educação: do senso comum à consciência filosófica. / Dermeval Saviani. - 18 revista - Campinas, SP: Autores Associados, 2009.

. Escola e Democracia: teorias da educação, curvatura da vara, onze teses sobre educação e política. Mercado das Letras. Campinas São Paulo. 1994.

O Legado Educacional do Regime Militar. Cad. Cedes, Campinas, vol. 28, n. 76, p. 291-312. 2008. 